\title{
Studies of intra-atrial conduction with bipolar atrial and His electrograms
}

\author{
R. N. Scott Millar, ${ }^{1}$ B. J. Maurer, D. S. Reid, ${ }^{2}$ R. Wray, ${ }^{3}$ J. S. Birkhead, \\ and J. P. Shillingford \\ From MRC Cardiovascular Research Unit, Royal Postgraduate Medical School, London
}

With the use of His bundle electrograms, intra-atrial conduction delay has been found to be a cause of firstdegree heart block. Twenty-one patients with evidence of atrioventricular conduction defects or dysrhythmias were studied with His bundle electrograms and 2 were found to have delayed intra-atrial conduction while in sinus rhythm. A further 3 patients had normal PA intervals during sinus rhythm but prolonged StA intervals during atrial pacing. The significance of this is discussed.

In view of the difficulty in timing the onset of atrial depolarization from the surface electrocardiogram, $a$ bipolar electrogram from the high right atrium recorded simultaneously with the His electrogram was used to time intra-atrial conduction in II patients. This interval was found to be significantly greater than the PA interval measured from the surface electrocardiogram. It is suggested that this be done routinely during recording of His bundle electrograms.

Since the introduction of His bundle electrocardiography in man (Scherlag et al., 1969), more detailed assessment of intracardiac conduction has become possible. Attention has been focused mainly on defects in the atrioventricular (AV) node and HisPurkinje system. Recently it has been shown that conduction defects also occur in the specialized conducting system of the atrium (Narula et al., 1970, I97I; James and Scherf, I97I ; Castellanos, Castillo, and Agha, 1971a). This finding has increased the importance of accurate measurement of the intra-atrial conduction time. This interval is usually measured as the time taken from the onset of the $\mathbf{P}$ wave on the surface electrocardiogram to the onset of the A deflection on the His electrogram, both traces being recorded simultaneously (PA time). Difficulty in timing the onset of the $P$ wave on the surface electrocardiogram, particularly at high recording speeds, makes accurate assessment of the PA interval difficult and can lead to considerable errors. To reduce these errors, a bipolar atrial

Received 14 November 1972.

${ }^{1}$ Present addresses: Cardiac Clinic, Johannesburg Hospital and University of Witwatersrand, Klein Street, Johannesburg, South Africa.

2 Cardiac Department, Newcastle General Hospital, Westgate Road, Newcastle upon Tyne NE4 6BE.

${ }^{3}$ Northwick Park Hospital, Watford Road, Harrow HAI 3 UJ, Middlesex. electrogram was recorded from the superior vena caval-right atrial junction simultaneously with the His electrogram. This measurement of intra-atrial conduction is termed the $P_{1} A$ interval and is compared with the standard method of measuring the PA interval using a surface electrocardiogram. The use of the high atrial electrogram also facilitates localization of supraventricular ectopic beats and the demonstration of retrograde conduction.

\section{Patients and methods}

Using the technique described by Scherlag et al. (1969), His bundle electrograms were recorded from 21 patients (aged 23 to 72 years) with evidence of atrioventricular conduction defects or dysrhythmias. Details of the findings in the individual patients are shown in Table $\mathrm{I}$.

The procedures used were explained in detail to all the patients studied and informed consent was obtained.

A bipolar electrode catheter was introduced percutaneously into the right femoral vein and positioned across the tricuspid valve. The electrogram was monitored as the tip of the catheter was slowly withdrawn until the characteristic His bundle deflection appeared between the atrial and ventricular deflections. A filter setting of $40-400 \mathrm{~Hz}$ was used on the electrocardiogram preamplifier, and recordings were made on a Cambridge multichannel oscilloscopic photographic recorder at a paper speed of $100 \mathrm{~mm} / \mathrm{sec}$. In 12 patients a separate bipolar electrode catheter was passed to the junction of the superior vena cava and the right atrium. This was 
TABLE I His electrograms in 2 I patients

\begin{tabular}{|c|c|c|c|c|c|c|}
\hline $\begin{array}{l}\text { Case } \\
\text { No. }\end{array}$ & $\begin{array}{l}\text { Age and } \\
\text { sex }\end{array}$ & $\begin{array}{l}P_{1} A \\
(m s e c)\end{array}$ & $\begin{array}{l}P A \\
(m s e c)\end{array}$ & $\begin{array}{l}A H \\
(m s e c)\end{array}$ & $\begin{array}{l}H V \\
\text { (msec) }\end{array}$ & Remarks \\
\hline $\mathbf{I}$ & $62 M$ & 30 & & 80 & 60 & $\begin{array}{l}\text { Left anterior hemiblock }+ \text { right bundle-branch block; anterior myo- } \\
\text { cardial infarction }\end{array}$ \\
\hline 2 & $58 \mathrm{~F}$ & 50 & & 75 & 65 & Intermittent left bundle-branch block \\
\hline 3 & $58 \mathrm{~F}$ & 40 & & IIO & 70 & Left bundle-branch block \\
\hline 4 & $62 \mathrm{M}$ & 45 & & 150 & 50 & First-degree heart block \\
\hline 5 & $60 \mathrm{~F}$ & 40 & & 80 & 40 & Left bundle-branch block \\
\hline 6 & $23 \mathrm{M}$ & 20 & & 100 & 40 & Ventricular ectopics \\
\hline 7 & $54 \mathrm{M}$ & 45 & & 80 & 35 & $\begin{array}{l}\text { Left anterior hemiblock }+ \text { right bundle-branch block; anteroseptal } \\
\text { myocardial infarction }\end{array}$ \\
\hline 8 & $49 \mathrm{M}$ & 40 & & 70 & 80 & $\begin{array}{l}\text { Left posterior hemiblock + right bundle-branch block; anterolateral } \\
\text { myocardial infarction }\end{array}$ \\
\hline 9 & $62 \mathrm{~F}$ & 30 & & 85 & 85 & Narrow QRS; block below His bundle; pacemaker implanted \\
\hline 10 & $55 \mathrm{M}$ & 50 & & 85 & 45 & - \\
\hline II & $38 \mathrm{~F}$ & 40 & & 85 & 45 & Junctional ectopics \\
\hline 12 & $66 \mathrm{~F}$ & $50-70$ & & 70 & 50 & Atrial dysrhythmias; sinus node disease \\
\hline 13 & $40 \mathrm{M}$ & & 20 & 70 & 80 & Left bundle-branch block \\
\hline 14 & $64 \mathrm{~F}$ & & 40 & 115 & 35 & Sinoatrial block; atrial dysrhythmias \\
\hline 15 & $48 \mathrm{M}$ & & 30 & 125 & 55 & $\begin{array}{l}\text { Left anterior hemiblock + right bundle-branch block; inferolateral } \\
\text { myocardial infarction }\end{array}$ \\
\hline 16 & $63 \mathrm{~F}$ & & 30 & 125 & 65 & $\begin{array}{l}\text { Left anterior hemiblock; sinoatrial block; inferior myocardial } \\
\text { infarction }\end{array}$ \\
\hline 17 & $65 \mathrm{M}$ & & 80 & 120 & 40 & Intermittent left bundle-branch block; inferior myocardial infarction \\
\hline 18 & $72 \mathrm{M}$ & & 40 & IIO & 70 & $\begin{array}{l}\text { Left bundle-branch block; intermittent complete heart block; pace- } \\
\text { maker implanted }\end{array}$ \\
\hline 19 & 6I F & & 45 & 85 & 40 & $\begin{array}{l}\text { Left anterior hemiblock; paroxysmal atrial flutter; anterior myo- } \\
\text { cardial infarction }\end{array}$ \\
\hline 20 & $60 \mathrm{M}$ & & 30 & 40 & 50 & Paroxysmal ventricular tachycardias; anterior myocardial infarction \\
\hline $2 I$ & $49 \mathrm{M}$ & & 40 & 70 & 90 & Left bundle-branch block \\
\hline
\end{tabular}

TABLE 2 Comparison of intra-atrial conduction as measured from high atrial electrogram $\left(P_{1} A\right)$ and surface $P$ wave $(P A)$

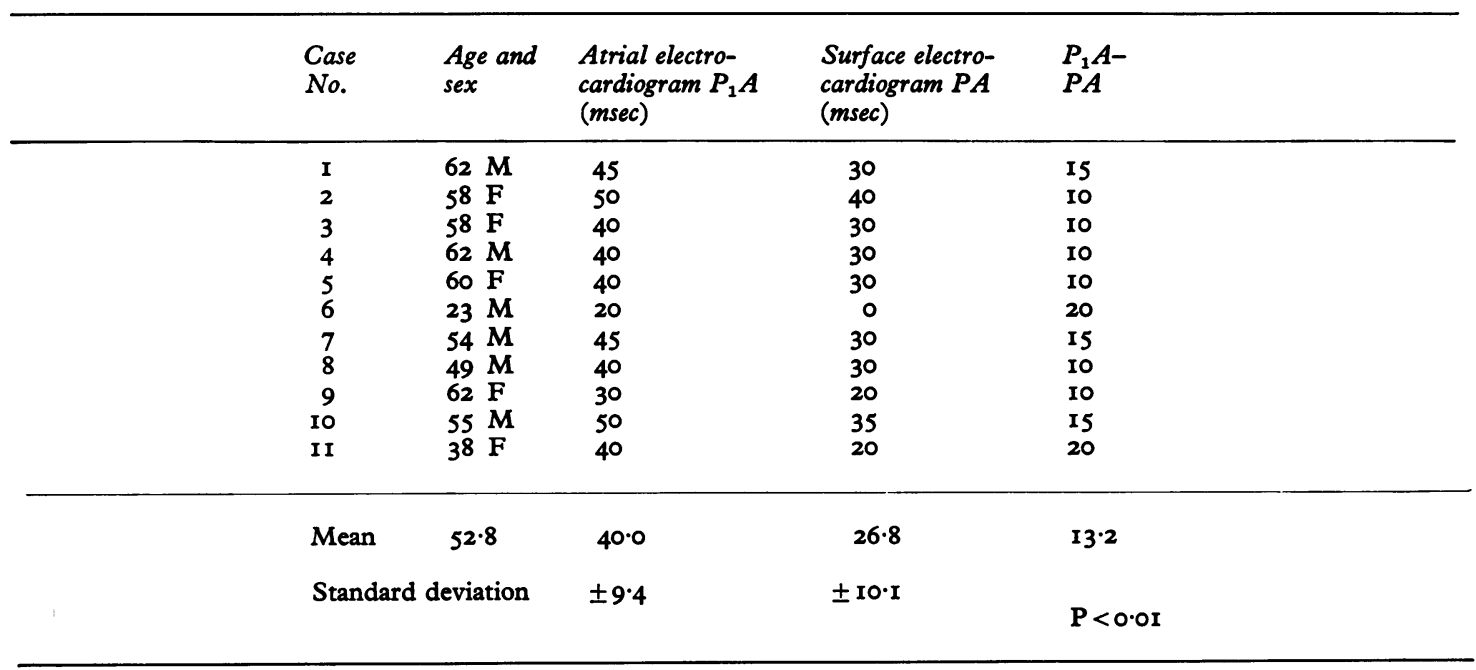


used to record a bipolar electrogram simultaneously with the His electrogram. The same catheter was used to pace the atrium at rates of up to 187 a minute, using a modified Devices external battery-powered pacemaker. Precautions were taken to isolate all equipment from leakage currents.

The first rapid deflection of the atrial electrogram $\left(P_{1}\right)$ was used to determine the onset of atrial depolarization and the interval to the atrial (A) deflection of the His electrogram was measured. This was compared with the PA interval measured from the beginning of the $P$ wave of the surface electrocardiogram (P). During atrial pacing the time from the pacing stimulus to the $A$ deflection (StA interval) was measured. The normal PA time is 20 to $40 \mathrm{msec}$; $\mathrm{AH}$ is 50 to $120 \mathrm{msec}$ and $\mathrm{HV}$ is 35 to $55 \mathrm{msec}$ (Narula et al., I97I ; Castellanos et al., 1971a).

In Cases I to II (Table 2), comparisons were made between the $P_{1} A$ and PA intervals. Case 12 was not included in the comparison because her PA interval varied from 50 to $70 \mathrm{msec}$. In 4 of the II patients (Cases 8,9 , IO, and II), simultaneous surface (lead II), high atrial, and $\mathrm{His}$ electrograms were obtained. In the remaining 7 patients the surface and His electrograms and the atrial and His electrograms were recorded consecutively. The heart rate varied by no more than 6 beats a minute between recordings in all patients except one (Case 5), in whom the heart rate was 68 a minute during the surface and $\mathrm{His}$ recording and 85 a minute during the atrial and His recording.

\section{Results}

Patients with abnormal intra-atrial conduction Of the 2 I patients studied, 2 (Cases 12 and 17) had a prolonged intra-atrial conduction time when in sinus rhythm and in neither was the defect greatly increased by atrial pacing. Case 12 was a 66-year-old woman with sinus node disease who presented with several episodes of supraventricular tachycardia and atrial fibrillation. At the time of the His electrogram, sinus bradycardia was present with extreme variation in sinus cycle length. A prolonged sinus recovery time of $3.8 \mathrm{sec}$ on cessation of atrial pacing was found. The $P_{1} A$ interval varied from 50 to $70 \mathrm{msec}$ (mean 60) with no apparent change in focus as judged from the $P$ wave configuration on the atrial electrogram. The StA time at a rate of I62 a minute ranged from 50 to $70 \mathrm{msec}$.

Case 17 showed intermittent left bundle-branch block and a prolonged PR interval (240 $\mathrm{msec})$. The $\mathrm{AH}$ (120 msec) and $\mathrm{HV}$ intervals were normal $(40 \mathrm{msec})$ but the PA was prolonged to $80 \mathrm{msec}$ (Fig. I). During atrial pacing the StA interval was IOO $\mathrm{msec}$ at 85 a minute. In 3 patients (Cases I4, I6, and I8) the PA intervals were normal but on atrial pacing StA intervals were prolonged ( $80 \mathrm{msec}$ or more).

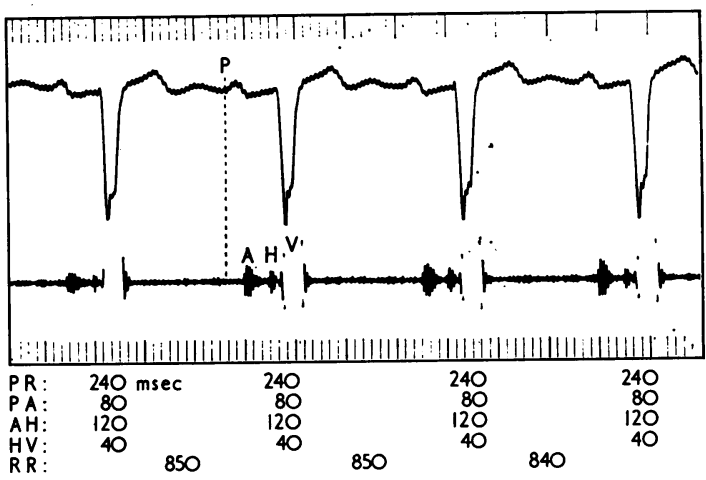

FIG. I Case I7. First-degree heart block due entirely to intra-atrial conduction delay.

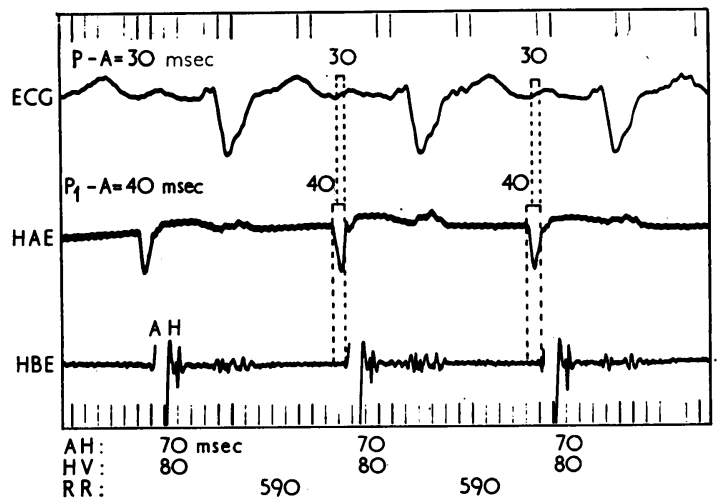

FIG. 2 Case 8. Surface electrocardiogram (lead II), high atrial electrogram (HAE), and His electrogram $(H B E)$, showing earlier atrial depolarization in $H A E$.

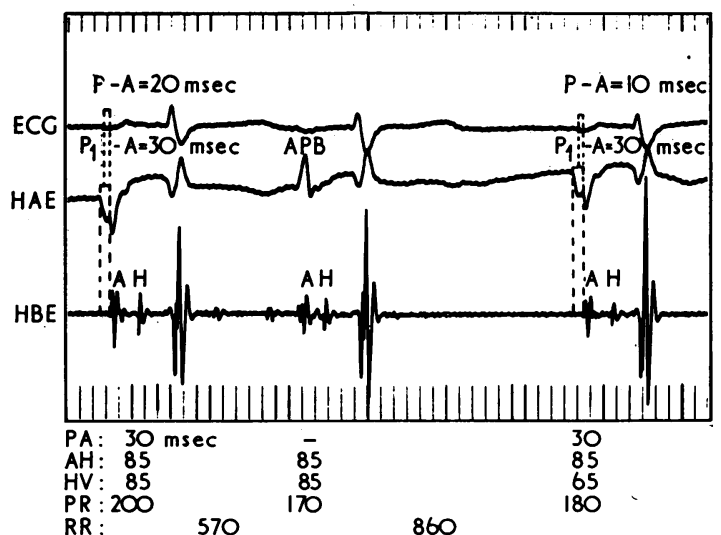

FIG. 3 Case 9. Electrocardiogram (lead II), high atrial electrogram (HAE), and His electrogram $(H B E)$, showing difficulty in determining onset of atrial depolarization from surface $P$ wave. The second complex is an atrial premature beat $(A P B)$. 
Case 14 was a 64 -year-old woman who presented with palpitations. Her surface electrocardiogram showed normal $P$ waves on occasions. At other times she had inverted $P$ waves in leads II, III, and aVF, frequent supraventricular ectopics, and occasional 3:2 sinoatrial block. Her PA was normal (40 $\mathrm{msec}$ ) but during atrial pacing StA was prolonged to $85 \mathrm{msec}$ at a rate of 85 a minute.

Case 16, a 63-year-old woman with a previous inferior myocardial infarction, prolonged PR interval, interpolated ventricular ectopic beats, sinus bradycardia, and sinoatrial block presented with an 18month history of blackouts. The His electrogram in sinus rhythm showed a PA interval of $30 \mathrm{msec}, \mathrm{AH}$ of $125 \mathrm{msec}$, and $\mathrm{HV}$ of $65 \mathrm{msec}$. Atrial pacing at 92 a minute resulted in an StA of $80 \mathrm{msec}$ which increased to $90 \mathrm{msec}$ at 133 a minute with $2: 1 \mathrm{AV}$ block proximal to the His bundle. The sinus recovery time after atrial pacing was slightly prolonged at $\mathrm{I} \cdot 6$ seconds. The findings suggest disease of the sinus node and delay in conduction involving the atrium, AV node, and His-Purkinje system.

Case 18 was a 72-year-old man who presented with Adams-Stokes attacks. His electrocardiogram showed sinus rhythm with a PR interval of $0.22 \mathrm{sec}$ and complete left bundle-branch block. Subsequent recordings showed intermittent complete heart block. When in sinus rhythm, the His electrogram showed a PA interval of $40 \mathrm{msec}, \mathrm{AH}$ of $110 \mathrm{msec}$, and $\mathrm{HV}$ of $70 \mathrm{msec}$. Atrial pacing at a rate of only 80 a minute resulted in an StA of $140 \mathrm{msec}$. This rose to $150 \mathrm{msec}$ at a rate of $\mathrm{I} 60$ a minute. A permanent demand pacemaker was subsequently inserted.

PA vs $P_{1} A$ The results in the I I patients studied are shown in Table 2. The $P_{1} A$ interval (measured from the atrial electrogram) ranged from 20 to 50 msec (mean 40) whereas the PA interval measured from the surface lead ranged from o-40 msec (mean 26.8). The difference between the two measurements was significant $(P<0 \cdot 01)$. In Case 6 , the $P A$ interval appeared to be $O$ when measured from the surface $P$ wave but the $P_{1} A$ interval was $20 \mathrm{msec}$. The $P_{1} A$ interval always exceeded the PA interval by at least ro msec. An example is shown in Fig. 2 of simultaneously recorded surface, high atrial (HAE), and His (HBE) electrograms from Case 8. Fig. 3 from Case 9 illustrates the difficulty that may occur in timing the onset of surface $P$ wave with consequent variation in the PA interval, in this case between $\mathrm{IO}$ and $20 \mathrm{msec}$.

\section{Discussion}

The use of His electrography has led to the recognition of conduction disturbances in the specialized conducting system of the atrium, as well as to the clarification of the more common atrioventricular blocks. Narula and his colleagues (197I) reported a patient who had a prolonged $P R$ interval due entirely to prolongation of intraatrial conduction; the PA time being Iro msec (normal 20-45 msec). Another patient reported by the same group also had a prolonged intra-atrial conduction time (PA of $100 \mathrm{msec}$ ) in association with impaired conduction in the AV junction (AH time $225 \mathrm{msec}$ ), His-Purkinje system (HV time 70 msec) and sinus bradycardia (Narula and Samet, I97I). These cases show that defects in intra-atrial conduction may occur alone or in association with disease in other parts of the conducting system. In this study we have found two patients with prolonged intra-atrial conduction. In Case I2, the association of an intra-atrial conduction defect, sinus node disease, paroxysmal supraventricular tachycardia, and atrial fibrillation suggests that atrial disease was responsible for the development of the dysrhythmias. It is of interest that her intra-atrial conduction time varied from 50 to $70 \mathrm{msec}$ even in beats which appeared to be arising from the same atrial focus, as judged by the configuration of the intra-atrial electrogram. The variation in the PA interval could be explained either by differential conduction through the atrium from two separate but adjacent atrial foci or by intermittent preferential conduction from the same focus (Narula et al., 1971). The variation was not related to $R R$ or PP intervals which varied considerably (from 830 to $1320 \mathrm{msec}$ ).

In Case 17, the prolonged PR interval and left bundle-branch block suggest the presence of trifascicular block. However, the His electrogram showed that the prolongation of the PR $(240 \mathrm{msec})$ was due to prolonged intra-atrial conduction (PA $80 \mathrm{msec}$ ) and the AH (120 msec) and HV (40 msec) times were normal. Thus, delayed intra-atrial conduction was responsible for apparent atrioventricular block. James and Scherf (I97I) have suggested that complete AV dissociation may occur with failure of the sinus impulse to be conducted to the $\mathrm{AV}$ node. They quoted three cases of AV dissociation in which the block was associated with conspicuous changes in the $P$ waves suggesting altered intra-atrial conduction. Unfortunately, His bundle electrograms were not available in their cases to localize the site of the block but this case confirms their hypothesis.

The recognition of the clinical importance of intra-atrial conduction has made accurate measurement of the PA interval more significant. The PA time, as measured from the earliest deflection of the $P$ wave on the surface electrocardiogram to the $A$ 
deflection of the His bundle electrogram, has been accepted as a measure of the conduction time from the SA node to the AV node (Narula et al., I97I). The surface electrocardiogram is, however, a poor indicator of the earliest atrial depolarization as there is commonly an isoelectric period before the $P$ wave of 10 to $25 \mathrm{msec}$ during which the atrium is already depolarizing (Waldo et al., 1970). Further difficulty in measurement results from the low amplitude and slow rise of the surface $P$ wave. This is aggravated by the high recording speeds necessary to measure conduction times in the distal conducting system. Thus, errors of up to $20 \mathrm{msec}$ in the PA time might occur when the surface electrocardiogram is used. This error is reduced by measurement from an intra-atrial electrocardiogram if the electrode is situated in the region of the SA node because the tracing obtained from the bipolar electrode at the SVC-RA junction shows a sharp deflection, the onset of which is easy to determine even at fast paper speed. In all II cases in which the comparison was made, the intra-atrial conduction time exceeded that measured from the surface electrocardiogram. In Case 6 , the onset of the surface $P$ wave appeared to coincide with the A deflection of the His electrogram but the $P_{1} A$ interval measured from the high atrial electrogram was $20 \mathrm{msec}$. The mean difference between the intervals measured by the two methods was $13.2 \mathrm{msec}$ and was significant at the I per cent level.

A further advantage of recording simultaneous intra-atrial and His electrograms is the more complete analysis of dysrhythmias with retrograde conduction. Retrograde $\mathbf{P}$ waves, often invisible on the surface electrocardiogram, are usually seen on the intra-atrial record and retrograde conduction can be timed. Further complex refinements have been described in man (Castellanos, Castillo, and Myerburg, 197Ib) and in the dog (Damato et al., 1970), but the use of a single intra-atrial electrode can provide useful information during more routine studies.

The significance of an StA interval during atrial pacing which is much longer than the PA interval during sinus rhythm is not clear. It has been claimed that atrial pacing at moderate rates may occasionally unmask intra-atrial conduction disturbances (Castellanos et al., I971a, Fig. 2). These authors report a patient with complete right bundle-branch block and left anterior hemiblock in whom the $P_{1} A$ interval was $30 \mathrm{msec}$ while in sinus rhythm, but the StA time during atrial pacing was $115 \mathrm{msec}$. Case 18 in our series is very similar, in that the PA time while in sinus rhythm was $40 \mathrm{msec}$ but the StA time at an atrial pacing rate of only $80 /$ minute was $140 \mathrm{msec}$. A lesser defect was unmasked in Cases I4 and 16 in whom pacing showed StA times of 85 and 80 msec with normal PA times. Each had evidence of sinoatrial node disease and suffered recurrent atrial dysrhythmias. The findings support the suggestion of Castellanos et al. (1971a) that a prolonged StA interval may represent a latent defect in atrial conduction.

Cases 16, 17, and 18 are also of considerable interest because of the association of sinoatrial nodal and atrial disease with disease in the AV node and His-Purkinje system. The fact that three instances were found in $2 \mathrm{I}$ patients suggests that this combination may be more frequent than previously realized.

Atrial pacing is employed routinely during His electrography to stress the conducting system and assess sinus node function (Damato et al., 1969a, b; Narula et al., I97I; Castellanos et al., I971a). The use of the pacing catheter to record a high intraatrial electrogram simultaneously with the His bundle electrogram does not involve any additional procedure. This allows more accurate assessment of the intra-atrial conduction time and is recommended for routine use in patients who are having conduction system studies. Atrial pacing may be of value in exposing latent defects in intra-atrial conduction but its value remains to be confirmed.

\section{References}

Castellanos, A., Castillo, C. A., and Agha, A. S. (1971a). Contribution of His bundle recordings to the understanding of clinical arrhythmias. American fournal of Cardiology, 28, 499.

Castellanos, A., Castillo, C. A., and Myerburg, R. J. (I97Ib). Bipolar coronary sinus lead for left atrial and left ventricular recording. American Heart Fournal, 81, 832.

Damato, A. N., Lau, S. H., Bobb, G. A., and Wit, A. L. (1970). Recording of A-V nodal activity in the intact dog heart. American Heart fournal, 80, 353.

Damato, A. N., Lau, S. H., Helfant, R., Stein, E., Patton, R. D., Scherlag, B. J., and Berkowitz, W. D. (1969a). A study of heart block in man using His bundle recordings. Circulation, 39, 297.

Damato, A. N., Lau, S. H., Patton, R. D., Steiner, C., and Berkowitz, W. D. (1969b). A study of atrioventricular conduction in man using premature atrial stimulation and His bundle recordings. Circulation, 40, 6r.

James, T. N., and Scherf, L. (I97I). Specialized tissues and preferential conduction in the atria of the heart. American fournal of Cardiology, 28, 414.

Narula, O. S., Cohen, L. S., Samet, P., Lister, J. W., Scherlag, B. J., and Hildner, F. J. (1970). Localization of A-V conduction defects in man by recording of the His bundle electrogram. American fournal of Cardiology, 25, 228.

Narula, O. S., and Samet, P. (I97I). Right bundle branch block with normal, left or right axis deviation: analysis by His bundle recordings. American fournal of Medicine, 5I, 432.

Narula, O. S., Scherlag, B. J., Samet, P., and Javier R. P., (I97I). Atrioventricular block: localization and classification by His bundle recordings. American fournal of Medicine, 50, 146. 
Scherlag, B. J., Lau, S. H., Helfant, R. H., Berkowitz, W. D., Stein, E., and Damato, A. N. (1969). Catheter technique for recording His bundle activity in man. Circulation, 39, 13.

Waldo, A. L., Vitikainen, K. J., Kaiser, G. A., Malm, J. R., and Hoffman, B. F. (1970). The P wave and P-R interval: effects of the site of origin of atrial depolarisation. Circulation, 42, 653 .

Requests for reprints to Dr. B. J. Maurer, MRC Cardiovascular Research Unit, Royal Postgraduate Medical School, London. 